Babette Peeters

Nicolaas J. G. Jansen

Casper W. Bollen

Adrianus J. van Vught

Douwe van der Heide

Marcel J. I. J. Albers

\section{Off-hours admission and mortality in two pediatric intensive care units without 24-h in-house senior staff attendance}

Received: 4 January 2010

Accepted: 16 July 2010

Published online: 19 August 2010

(C) The Author(s) 2010. This article is published with open access at Springerlink.com

This work was presented, in part, as an oral presentation at the 20th Medical and Nursing Congress of the European Society for Pediatric and Neonatal Intensive Care, June 2009, Verona, Italy.

B. Peeters · N. J. G. Jansen $(\bowtie)$.

C. W. Bollen - A. J. van Vught

Pediatric Intensive Care Unit,

Wilhelmina Children's Hospital,

University Medical Center Utrecht,

P.O. Box 85090, 3508 AB Utrecht,

The Netherlands

e-mail: n.j.g.jansen@umcutrecht.nl

Tel.: +31-88-7554002

Fax: +31-88-7555340

D. van der Heide - M. J. I. J. Albers

Pediatric Intensive Care Unit,

Beatrix Children's Hospital,

University Medical Center Groningen,

Groningen, The Netherlands
Abstract Purpose: To compare risk-adjusted mortality of children non-electively admitted during offhours with risk-adjusted mortality of children admitted during office hours to two pediatric intensive care units (PICUs) without 24-h in-house attendance of senior staff.

Design: Prospective observational study, performed between January 2003 and December 2007, in two PICUs without 24-h in-house attendance of senior staff, located in tertiary referral children's hospitals in the Netherlands. Methods: Standardized mortality rates (SMRs) of patients admitted during off-hours were compared to SMRs of patients admitted during office hours using Pediatric Index of Mortality (PIM1) and Pediatric Risk of Mortality (PRISM2) scores. Office hours were defined as week days between 8:00 a.m. and 6:00 p.m., with in-house attendance of senior staff, and off-hours as week days between 6:00 p.m. and 8:00 a.m., Saturdays, Sundays and public holidays, with one resident covering the PICU and senior staff directly available on-call. Results: Of 3,212 non-elective patients admitted to the PICUs, 2,122 (66\%) were admitted during offhours. SMRs calculated according to PIM1 and PRISM2 did not show a significant difference with those of patients admitted during office hours. There was no significant effect of admission time on mortality in multivariate logistic regression with odds ratios of death in off-hours of 0.95 (PIM1, 95\% CI 0.71-1.27, $p=0.73$ ) and 1.03 (PRISM2, 95\% CI 0.76-1.39, $p=0.82$ ). Conclusion: Off-hours admission to our PICUs without 24-h in-house attendance of senior staff was not associated with higher SMRs than admission during office hours when senior staff were available in-house.

Keywords Pediatric critical care Mortality - Outcome - Staffing · Admission time - Quality of care

\section{Introduction}

During the last few years there has been increasing discussion about the factors that determine the quality of care provided in hospitals during so called "off-hours". It is known that adequate care during the first hours is of major importance for the outcome of patients admitted to intensive care units (ICUs) [1, 2]. In many ICUs, however, there is no 24-h in-house attendance of senior staff. A significant effect of admission time on the risk-adjusted mortality of patients has been found in some adult ICUs without 24-h coverage by senior staff [3-5]. This has led to an increasing trend towards 24-h ICU coverage by in-house intensivists in adult intensive care medicine [6].

Studies in pediatric intensive care medicine are sparse and have yielded contradictory results. Some authors have 
found off-hours admission to a pediatric ICU (PICU) to be associated with higher mortality rates, whereas other authors have found off-hours mortality rates to be equal to or even lower than office hours mortality rates [7-9].

We hypothesized that the direct on-call availability of senior staff during off-hours would not result in higher risk-adjusted PICU mortality rates when compared to in-house attendance of senior staff. Therefore, we compared the risk-adjusted mortality rates of patients admitted non-electively during office hours with those of patients admitted non-electively during off-hours in two level III PICUs without 24-h in-house attendance of senior staff.

\section{Methods}

Data from two level III PICUs in tertiary referral children's hospitals in the Netherlands were prospectively collected from the dataset of the national audited Pediatric Intensive Care Evaluation (PICE) database. The Institutional review board waived the need for informed consent.

Both PICUs are situated in university teaching hospitals, in Utrecht and Groningen, and have multidisciplinary and comparable patient populations. The total number of beds in the PICUs was 14 and 10, respectively. Data registration was performed by trained staff and medical students. Demographics, medical history, mortality prediction score items, Australia and New Zealand Pediatric Intensive Care (ANZPIC) Registry diagnostic codes, ventilation days and admission and discharge information were anonymously collected from the database and used to calculate the riskadjusted predicted mortality according to the Pediatric Index of Mortality-1 (PIM1) and the Pediatric Risk of Mortality-2 (PRISM2) algorithms [10-12].

All patients from 0 to 18 years of age who were nonelectively admitted to one of the two PICUs between January 2003 and December 2007 were included. Non-elective admission was defined as an admission that could not be postponed for more than $6 \mathrm{~h}$. Office hours were defined as week days (Monday to Friday) from 8:00 a.m. to 6:00 p.m. Off-hours were defined as week days from 6:00 p.m. to 8:00 a.m., Saturdays, Sundays and public holidays.

Both PICUs had a comparable staffing model. During office hours, senior staff were present in the units together with two residents with an average of 4 years experience in pediatrics, with no duties other than PICU-related patient care. During off-hours, one experienced resident was covering the PICU with no duties other than PICU-related patient care. The senior staff member on duty during offhours would see all unstable patients and personally supervise all admissions and critical procedures including endotracheal intubation and insertion of central venous and arterial lines, but would not routinely be present at the PICU. The senior staff member would be able to come into the PICU within 15 min. Most of the time, the senior staff member on duty was a pediatric intensivist. Other times, a pediatrician, pediatric anesthesiologist, pediatric pulmonologist or cardiologist with experience in critical care was on duty with a pediatric intensivist on standby. An extra senior staff member was on standby in case of emergencies or when a patient needed to be transported. Throughout the study period there were no changes in the staffing models of medical or nursing staff.

The primary endpoint of this study was PICU mortality. By dividing the observed mortality by the riskadjusted predicted mortality, standardized mortality rates (SMRs) were calculated. Secondary endpoints were ventilator days and length of stay in the PICU.

Statistical analysis was performed using SPSS version 16.0.2. (SPSS, Chicago IL). Independent $t$ tests were performed to compare continuous variables and chi-squared tests for dichotomous variables. Skewed data are reported as medians with interquartile ranges. The Wald approximation by Rothman and Greenland [13] was used for calculation of $95 \%$ CIs for the SMRs. Multivariable logistic regression analysis was performed to evaluate the differences between the two centers as to the effect of off-hours admission on mortality. In this analysis, mortality was the dependent variable. Along with center of admission, PIM1 and PRISM2 variables were entered into two separate analyses. In the multivariable logistic regression analysis using PIM1, postoperative status and age in months were added as independent variables as well, since these variables are part of the PRISM2 algorithm, but not of the PIM1 algorithm. A $p$ value $<0.05$ was considered statistically significant.

\section{Results}

Between January 2003 and December 2007, 3,212 out of a total of 5,672 patients were non-electively admitted to the PICUs of Utrecht and Groningen. Of these patients, 2,122 (66\%) were admitted during off-hours. The patient characteristics are summarized in Table 1. Patients admitted during off-hours were slightly older than those admitted during office hours. More postoperative patients were admitted during office hours. During off-hours, a lower percentage of patients were admitted because of hemodynamic instability ( $17 \%$ vs. $20 \%, p=0.02)$ and a higher percentage because of (multi)trauma (12\% vs. 6\%, $p<0.001$ ). Both the numbers of patients admitted and the patient characteristics of the two PICUs were very similar.

The mortality observed in the off-hours group was $8.5 \%$ and in the office hours group $7.9 \%$. The overall mortality predicted by the PRISM2 algorithm was higher than that predicted by the PIM1 algorithm (Table 1). The PIM1-based SMR was 1.04 (95\% CI 0.89-1.20) for the off-hours group and 0.99 (95\% CI $0.80-1.22)$ for the office hours group (Table 2). The PRISM2-based SMR 
Table 1 Patient characteristics

\begin{tabular}{|c|c|c|c|c|}
\hline & All patients & Office hours & Off-hours & $p$ value \\
\hline Number of patients & 3,212 & 1,090 & 2,122 & \\
\hline Male & $1,798(56 \%)$ & $589(54 \%)$ & $1,200(57 \%)$ & ns \\
\hline \multicolumn{5}{|l|}{ Age (months) } \\
\hline Median & 24.6 & 17.1 & 28.0 & \multirow[t]{2}{*}{0.001} \\
\hline Interquartile range & $4-80$ & $3-80$ & $5-101$ & \\
\hline \multicolumn{5}{|l|}{ PICU length of stay (days) } \\
\hline Median & 2.6 & 2.9 & 2.5 & \multirow[t]{2}{*}{ ns } \\
\hline Interquartile range & $0.9-6.8$ & $1-7.7$ & $0.8-6.5$ & \\
\hline \multicolumn{5}{|l|}{ Ventilator days } \\
\hline Median & 2 & 2 & 2 & \multirow[t]{2}{*}{ ns } \\
\hline Interquartile range & $0-6$ & $0-6$ & $0-6$ & \\
\hline Observed PICU mortality & $267(8.3 \%)$ & $86(7.9 \%)$ & $181(8.5 \%)$ & ns \\
\hline \multicolumn{5}{|l|}{ Predicted mortality } \\
\hline PIM1 & $8.2 \%$ & $8.0 \%$ & $8.2 \%$ & $\mathrm{~ns}$ \\
\hline PRISM2 & $11.8 \%$ & $10.9 \%$ & $12.2 \%$ & ns \\
\hline \multicolumn{5}{|l|}{ Admission type } \\
\hline Postoperative $^{\mathrm{a}}$ & $520(16 \%)$ & $196(18 \%)$ & $324(15 \%)$ & 0.049 \\
\hline Respiratory & $1,119(35 \%)$ & $390(36 \%)$ & $729(34 \%)$ & $\mathrm{ns}$ \\
\hline Hemodynamic & $569(18 \%)$ & $217(20 \%)$ & $352(17 \%)$ & 0.02 \\
\hline Neurological & $172(5 \%)$ & $49(5 \%)$ & $123(6 \%)$ & ns \\
\hline Trauma & $324(10 \%)$ & $63(6 \%)$ & $261(12 \%)$ & $<0.001$ \\
\hline Other & $508(16 \%)$ & $175(16 \%)$ & $333(16 \%)$ & $\mathrm{ns}$ \\
\hline
\end{tabular}

$n s$ Not significant

a Includes cardiopulmonary (bypass) surgery
Table 2 SMRs and 95\% CI for all non-elective patients

\begin{tabular}{lll}
\hline Score & \multicolumn{2}{l}{ SMR } \\
\cline { 2 - 3 } & Office hours & Off-hours \\
\hline PIM1 & $0.99(0.80-1.22)$ & $1.04(0.89-1.20)$ \\
PRISM2 & $0.72(0.59-0.90)$ & $0.69(0.60-0.80)$ \\
\hline
\end{tabular}

was 0.69 (95\% CI 0.60-0.80) for the off-hours group and 0.72 (95\% CI $0.59-0.90)$ for the office hours group.

Multivariable logistic regression analyses with mortality as the dependent variable showed no significant effect of off-hours admission on mortality (Table 3 ). A significant effect of postoperative status on mortality was seen in the PIM1 analysis as an odds ratio of 1.59 (95\% CI 1.02-2.50). Apart from that, mortality was only significantly affected by the prediction scores. No center-specific effect on mortality was found in the regression analyses.

There was a wide variation in the secondary endpoints ventilator days and length of stay, but no difference was found between the off-hours and office hours groups (Table 1). Redoing these analyses, with Saturdays, Sundays and public holidays from 8:00 a.m. to 12:00 p.m. defined as office hours, or with inclusion of elective patients, yielded essentially identical results (data not shown).

\section{Discussion}

In this prospective 5-year study conducted in two level III PICUs, in non-electively admitted patients direct on-call
Table 3 Logistic regression analyses, mortality as dependent variable

\begin{tabular}{llll}
\hline & Odds ratio & $95 \%$ CI & $p$ value \\
\hline PIM1 in analysis & & & \\
Off-hours admission & 0.95 & $0.71-1.27$ & $\mathrm{~ns}$ \\
Expected mortality & 1.06 & $1.05-1.07$ & $<0.001$ \\
Center (1) & 0.79 & $0.60-1.05$ & $\mathrm{~ns}$ \\
Postoperative (1) & 1.59 & $1.02-2.50$ & 0.04 \\
Age (months) & 1.0 & $0.99-1.00$ & $\mathrm{~ns}$ \\
PRISM2 in analysis & & & \\
Off-hours admission & 1.03 & $0.76-1.39$ & $\mathrm{~ns}$ \\
Expected mortality & 1.05 & $1.04-1.05$ & 0.047 \\
Center (1) & 0.80 & $0.60-1.07$ & $\mathrm{~ns}$ \\
\hline
\end{tabular}

$n s$ Not significant

${ }^{a}$ Center (1): PICU Utrecht as reference

b Postoperative (1): Yes

availability of senior staff during off-hours did not result in higher SMRs than when senior staff were available inhouse during office hours. Mortality was only affected by the mortality prediction scores PIM1 and PRISM2, and by the postoperative status of the patients. Off-hours admission did not result in an increased number of ventilator days or an increased length of PICU stay.

Previously conducted studies on the effect of off-hours in-house attendance of senior staff on pediatric intensive care mortality used various definitions of "off-hours" and yielded contradictory results. Arias et al. [7] found higher mortality rates in specific groups of patients admitted to 15 different PICUs in the US during off-hours. However, no information about availability of staff during these hours was provided. Hixson et al. [8] reported no significant effect 
of off-hours admission on mortality in 5,968 patients admitted to a single PICU with continuous in-house attendance of senior staff, and concluded that patients benefit from 24-h in-house attendance of senior staff. Numa et al. [9] studied 4,456 non-elective pediatric patients admitted to one PICU without 24-h coverage by an in-house intensivist and found lower risk-adjusted mortality rates and shorter lengths of stay for admissions during off-hours. Our results are in line with those reported by Numa et al. [9], and may reflect the presence of senior staff at the time of admission of a patient during off-hours. In our PICUs, when admission of a severely ill patient is being announced, the resident will immediately contact the senior staff member on call so that a senior staff member is present when patients with a medium or high risk of mortality are admitted.

In postoperative patients, PIM1-based prediction of offhours' mortality was significantly higher than office hours mortality. This might be have been due to the fact that, in the PIM1 algorithm, the postoperative status is not part of the scoring system, in contrast to the PRISM2 algorithm.

Our study has several limitations. In the first place, our results might have been influenced by our decision to include only non-elective patients and to treat Saturdays, Sundays and public holidays as off-hours. We assumed that the concepts of the so-called golden hour and of early goaldirected therapy would apply most to non-elective PICU admissions [1, 2, 14]. Elective admissions, on the other hand, constituted only a small proportion of all off-hours admissions; most were an overrun of procedures scheduled for office hours, and had a low predicted mortality rate. Indeed, when we included elective admissions in the analyses, the results were essentially identical (data not shown). Similarly, expanding the definition of office hours to include the morning rounds of Saturdays, Sundays and public holidays when senior staff would as a rule be present in the PICU, did not change the results (data not shown).

Secondly, we used the older PIM1 and PRISM2 algorithms to calculate SMRs, not their successors (PIM2 and PRISM3). At the beginning of the study period in 2003 the Dutch PICUs had not yet decided to include PIM2 in the PICE dataset $[15,16]$. Therefore, PIM2 scores were not available for the whole study period. PRISM3 scores were not used because of the high cost of obtaining the algorithm. Although the calibration characteristics of the PIM1 and PRISM2 algorithms might be inferior to those of their successors, both algorithms have good discriminative characteristics, are still widely used, and have been validated for use in the Netherlands [17-19]. PRISM2 has been used in all Dutch PICUs from 2003 and consistently overpredicted mortality, as in other studies [20, 21]. Keeping these limitations in mind, however, the validity of our findings is supported by the fact that both PIM1 and PRISM2 yielded the same results.

Finally, the level of cover by senior staff during off-hours in our units is high, as senior staff will see all unstable patients and supervise admissions and critical procedures. Moreover, requiring senior staff to be able to come into the PICU within 15 min when on call imposes limits on hometo-work travelling time. This may limit the applicability of our findings in other settings than ours. Therefore, our results should be extrapolated to other PICUs with caution. We do not wish to imply that 24-h in-house attendance of senior staff is redundant or that on-call availability of senior staff will lead to enhanced outcome in PICUs. More studies are needed to establish the effects of different staffing models on the outcome of PICU patients. These studies should focus on other outcome measures such as complications, adverse events, patient and parent satisfaction and morbidity, since mortality is only a rough measure of outcome. Finally, other aspects of different staffing models such as cost effectiveness and feasibility should be endpoints of such studies.

\section{Conclusion}

Off-hours admission to our PICUs without 24-hour in-house attendance of senior staff was not associated with higher SMRs.

Acknowledgments The authors would like to thank Dr. I. Visser, researcher of the Dutch Pediatric Intensive Care Evaluation (PICE) database, for his help in obtaining the study data. The authors also thank all staff members and medical students without whose efforts the PICE data registration and this work would not have been possible. The authors have no conflicts of interest to disclose. Project support was entirely from institutional departmental funds.

Open Access This article is distributed under the terms of the Creative Commons Attribution Noncommercial License which permits any noncommercial use, distribution, and reproduction in any medium, provided the original author(s) and source are credited.

\section{References}

1. Gross PA (2006) Hypotension and mortality in septic shock: the "golden hour". Crit Care Med 34:1819-1820

2. Stroud MM, Prodhan P, Moss MM (2008) Redefining the golden hour in pediatric transport. Pediatr Crit Care Med 9:435-437
3. Uusaro A, Kari A, Ruokonen E (2003) The effects of ICU admission and discharge times on mortality in Finland. Intensive Care Med 29:2144-2148
4. Barnett MJ, Kaboli PJ, Sirio CA, Rosenthal GE (2002) Day of the week of intensive care admission and patient outcomes: a multisite regional evaluation. Med Care 40:530-539 
5. Laupland KB, Shahpori R, Kirkpatrick AW, Stelfox HT (2008) Hospital mortality among adults admitted to and discharged from intensive care on weekends and evenings. J Crit Care 34:605-611

6. Arabi Y (2008) Pro/con debate: should 24/7 in-house intensivist coverage be implemented? Crit Care 12:216

7. Arias Y, Taylor DS, Marcin JP (2004) Association between evening admissions and higher mortality rates in the pediatric intensive care unit. Pediatrics 113:e530-e534

8. Hixson ED, Davis S, Morris S, Harrison AM (2005) Do weekends or evenings matter in a pediatric intensive care unit? Pediatr Crit Care Med 6:523-530

9. Numa A, Williams G, Awad J, Duffy B (2008) After-hours admissions are not associated with increased risk-adjusted mortality in pediatric intensive care. Intensive Care Med 34:148-151

10. Slater A, Shann F, McEniery J; ANICS Study Group (2003) The ANZPIC registry diagnostic codes: a system for coding reasons for admitting children to intensive care. Intensive Care Med 29:271-277
11. Shann F, Pearson G, Slater A, Wilkinson K (1997) Pediatric Index of Mortality (PIM): a mortality prediction model for children in intensive care. Intensive Care Med 23:201-207

12. Pollack MM, Ruttimann UE, Getson RR (1988) Pediatric risk of mortality (PRISM) score. Crit Care Med 16:110-116

13. Rothman KJ, Greenland S (1998) Modern epidemiology. LippincottRaven, Philadelphia

14. Rivers E, Nguyen B, Havstad S, Ressler J, Muzzin A, Knoblich B, Peterson E, Tomlanovich M; Early Goal-Directed Therapy Collaborative Group (2001) Early goal directed therapy in the treatment of severe sepsis and septic shock. N Engl J Med 345:1368-1377

15. Slater A, Shann F, Pearson G (2003) PIM2: a revised version of the Pediatric Index of Mortality. Intensive Care Med 29:278-285

16. Pollack MM, Patel KM, Ruttimann UE (1996) PRISMIII: an updated pediatric risk of mortality score. Crit Care Med 24(5):743-752
17. Gemke RJ, Van Vught J (2002) Scoring systems in pediatric intensive care: PRISM III versus PIM. Intensive Care Med 28:204-207

18. Shann F (2002) Are we doing a good job: PRISM, PIM and all that. Intensive Care Med 28:105-107

19. Van Keulen JG, Polderman KH, Gemke RJ (2005) Reliability of PRISM and PIM scores in pediatric intensive care. Arch Dis Child 90:211-214

20. Visser IH; Dutch PICE Study Group (2008) PICE Report 2003-2005: Dutch pediatric intensive care evaluation. Stichting PICE, Rotterdam

21. Slater A, Shann F; ANZICS Paediatric Study Group (2004) The suitability of the Pediatric Index of Mortality (PIM), PIM2, the Pediatric Risk of Mortality (PRISM), and PRISM III for monitoring the quality of pediatric intensive care in Australia and New Zealand. Pediatr Crit Care Med $5: 447-454$ 